\title{
ОПРЕДЕЛЕНИЕ ГАЛЛОВОЙ КИСЛОТЫ В МНОГОКОМПОНЕНТНЫХ РАСТИТЕЛЬНЫХ СРЕДСТВАХ МЕТОДОМ ВЭЖХ
}

\author{
() П.Б. Лубсандоржиева ${ }^{1 *}$, Н.Б. Болданова ${ }^{2}$, Д.В. Попов ${ }^{2}$ \\ ${ }^{1}$ Институт общей и экспериментальной биологии СО РАН, \\ ул. Сахъяновой, 6, Улан-Удэ, 670047 (Россия) \\ ${ }^{2}$ Байкальский институт рационального природопользования СО РАН, \\ ул. Сахъяновой, 6, Улан-Удэ, 670047 (Россия), e-mail: bpunsic@mail.ru
}

\begin{abstract}
Определено содержание галловой кислоты в многокомпонентных сборах и эритрофите методом ВЭЖХ. Наибольшее количество галловой кислоты содержится в сборах, в состав которых входят листья Bergenia crassifolia (L.) Fritsch., Urtica dioica L., Mentha piperita L., плоды Hippophae rhamnoides L.

Ключевые слова: галловая кислота, метод ВЭЖХ, Bergenia crassifolia (L.) Fritsch., Urtica dioica L., Mentha piperita L., Hippophae rhamnoides L.
\end{abstract}

\section{Введение}

Галловая (3,4,5-триоксибензойная) кислота (ГК) является строительным материалом для гидролизуемых таннинов, содержится в растениях в свободном виде, в составе сложных эфиров. ГК и ее производные обладают антимикробным, противовоспалительным, иммуномодулирующим, антимутагенным, антираковым, гастропротективным, адренопролонгирующим свойствами [1-4]. Экспериментальные исследования показали, что это соединение способно индуцировать выработку оксида азота для макрофагов и активацию иммунокомпетентных клеток, потенцировать выработку интерферона клетками (защита клеток от инфекции), поддерживать адаптационно-трофическую функцию симпатической нервной системы [3]. Однако, являясь сильным антирадикальным соединением, ГК и ее производные могут проявлять прооксидантные свойства в больших концентрациях в присутствии ионов металла, и механизм этого действия связан с их сильной восстанавливающей и слабой металл-хелатирующей активностью $[4,5]$. Также ГК способно связываться с белками, ионами ключевых для организма металлов, такими как железо, цинк, кальций, образуя с ними нерастворимые комплексы и снижая их биодоступность [2]. Изучение метаболизма ГК показало, что основным метаболитом является 4-О-метилгалловая кислота, обнаруживаемая в крови в течение 6 ч с последующим выведением с мочой [6]. Известно, что $\mathrm{LD}_{50}$ для ГК у кроликов составляет 5000 мг/кг, а длительное введение 0,2\% ГК в течение 13 недель подопытным крысам линии F344 вызывало анемию, вероятно, гемолитического происхождения и гипертрофию клетки печени [2].

Лубсандоржиева Пунщык-Нима Базыровна - старший научный сотрудник лаборатории медикобиологических исследований, кандидат фармацевтических наук, e-mail: bpunsic@mail.ru Болданова Наталья Батлаевна - старший научный сотрудник лаборатории химии природных систем, кандидат биологических наук

Попов Дмитрий Витальевич - аспирант лаборатории химии природных систем
Для определения ГК в растительных, пищевых и технических объектах применяют спектрофотометрический, ТСХ-денситометрический, электрофоретический, ВЭЖХ $[7,8]$ методы.

Цель данной работы - определение количественного содержания галловой кислоты в многокомпонентных растительных средствах методом ВЭЖХ.

\footnotetext{
* Автор, с которым следует вести переписку.
} 


\section{Экспериментальная часть}

В состав сбора №1 для лечения алкогольного гепатита и абстинентного синдрома входят листья Vaccinium vitis-idaea L. и Mentha piperita L., трава Gnaphalium uliginosum L.s.1., плоды Rosa и Crataegus, корневища и корни Inula helenium L., корни Eleutherococcus senticosus Rupr. Et Maxim. B состав сбора №2 для лечения патологического влечения к алкоголю входят корневища Acorus calamus L., трава Achillea millefolium L., Artemisia absinthicum L., Thymus vulgaris L., цветы Tanacetum vulgaris L., листья Urtica dioica L. B состав сбора № 3 для лечения алкогольного гепатита с сопутствующим колитом входят черные листья и корни Bergenia crassifolia (L.) Fritsch., листья M. piperita L., цветки Calendula officinalis L., побеги Pentaphylloides fruticosa (L.) Schwarz, M., корни Scutellaria baicalensis Georgi. В состав сбора №4 для лечения и профилактики гиперлипидемии входят черные листья B. crassifolia, цветки Matricaria recutita L., трава Polygonum aviculare L., плоды Rosa L. и Crataegus L., корни A. calamus L. и Taraxacum officinale Wigg. В состав сбора №5 для лечения и профилактики язвенной болезни желудка и 12-перстной кишки входят цветки C. officinalis L., плоды Rosa L., Coriandrum sativum L., Hippophae rhamnoides L., и Crataegus L., корни и корневища I. helenium L., Glycyrrhiza glabra L., листья Plantago major L., трава Gnaphalium uliginosum L. B состав сбора № 6 для лечения и профилактики хронического колита входят черные листья B. crassifolia, листья M. piperita, цветки M. recutita, трава A. millefolum L. В состав эритрофита входят экстракты сухие из травы A. millefolium L., P. aviculare L., листьев $U$. dioica L., мелкоизмельченные порошки из корневищ Zingiber officinalis Roscoe, коры Cinnamomum cassia L. Фармакопейное сырье для сборов приобретено в аптечной сети, листья В. crassifolia собраны в осенне-весенний период на хребте Хамар-Дабан (Иволгинский район) и Улан-Бургасы (Прибайкальский район) в Бурятии в период 2008-2010 гг.

3-5 г сбора (точная навеска) или 1 г (точная навеска) средства, содержащего экстракты сухие, обрабатывали дважды по 25 мл гексана, затем по 25 мл хлороформа (3-кратная экстракция) для удаления липофильных веществ. Шрот экстрагировали последовательно 80\%, 40\% этиловым спиртом, трижды горячей водой по 25 мл, извлечения отфильтровали, спирт удалили, водный остаток концентрировали до 10-15 мл. Водный остаток обработали 30 мл этилацетата (пятикратно), извлечения отделяли от водного слоя, растворитель удалили, сухой остаток этилацетатной фракции растворили в 10-50 мл (точный объем) 96\% этилового спирта.

0,001 г (точная навеска) хроматографически чистого образца галловой кислоты растворили в 10 мл 96\% спирта этилового, путем разведения приготовили раствор ГК с концентрацией 10 мкг/мл.

Качественный и количественный состав в исследуемых образцах определяли методом ВЭЖХ-МС, с помощью высокоэффективного жидкостного хроматографа марки «Agilent 1200», с тандемным массспектрометрическим детектором «ионная ловушка» 6330, способ ионизации электроспрей. Колонка Zorbax Eclipse C18, 5 мкм, 4,6×150 мм. Элюирование проводили в градиентном режиме, в качестве подвижной фазы использовали смесь $0,1 \%$ раствора муравьиной кислоты и ацетонитрила в соотношении $(1: 0,1: 9$, 9 : 1). Объемная скорость потока элюента - 1,0 мл/мин, объем вводимой пробы 10 мкл, время элюирования 30 мин. Анализ проводился в режиме регистрации отрицательных ионов, по полному ионному току ТIC, по массовым зарядам характеристических (MS) и дочерних (MS2) отрицательных ионов, режим UltraScan 50$1300 \mathrm{~m} / \mathrm{z}$, AutoMS.

В хроматограф вводили по 20 мкл исследуемых растворов и раствора галловой кислоты, хроматографировали в выше приведенных условиях при 212 нм.

ТСХ анализ ГК в изучаемых объектах проводили на пластинках с силикагелем в системах растворителей хлороформ - этилацетат - уксусная кислота $(50: 50: 1)$ (I), этилацетат - муравьиная кислота - уксусная кислота - вода (100: $11: 11: 26)$ (II), гексан - этилацетат - муравьиная кислота (15:9:2) (III). Объем пробы этилацетатной фракции, наносимой на пластинку - 0,05 мл, проявляющий реагент - $1 \%$ ванилин в серной кислоте (конц.) Количественное содержание таннинов в водных извлечениях средств определено перманганатометрическим методом.

\section{Обсуждение результатов}

ГК проявляется на пластинках с силикагелем на уровне достоверного образца в виде пятна серого (видимый свет), коричневого (в УФ свете до проявления реагентом) и фиолетово-красного цвета (в УФ свете после проявления) с $\mathrm{R}_{\mathrm{f}}-0,20-0,26$ (I), 085-0,95 (II), 0,26-0,35 (III) в этилацетатной фракции сборов №3, 4, 5, 6, эритрофите и не обнаруживается в сборах №1, 2.

Данные анализов этилацетатной фракции исследуемых объектов методом ВЭЖХ приведены в таблице. 
Содержание таннинов и галловой кислоты в многокомпонентных сборах и эритрофите

\begin{tabular}{|c|c|c|c|}
\hline \multirow{2}{*}{ Наименование } & \multirow{2}{*}{$\begin{array}{c}\text { Содержание } \\
\text { танинов*, в \% }\end{array}$} & \multicolumn{2}{|c|}{ Содержание галловой кислоты (метод ВЭЖХ) } \\
\hline & & RT, мин & Содержание галловой кислоты, мкг / в 1 г средства** \\
\hline Сбор 1 & $3,52 \pm 0,01$ & $2,3-2,7$ & 2,586 \\
\hline Сбор 2 & $4,32 \pm 0,08$ & $2,3-2,5$ & 1,666 \\
\hline Сбор 3 & $7,53 \pm 0,31$ & $2,2-2,9$ & 3,139 \\
\hline Сбор 4 & $3,00 \pm 0,01$ & $2,3-2,8$ & 4,206 \\
\hline Сбор 5 & $2,20 \pm 0,01$ & $2,4-2,7$ & 5,834 \\
\hline Сбор 6 & $9,45 \pm 0,11$ & $2,3-2,8$ & 8,501 \\
\hline Эритрофит & $4,72 \pm 0,03$ & $1,7-2,7$ & 43,754 \\
\hline
\end{tabular}

ГК (стандартный образец) элюируется при 2,5 мин, из исследуемых растворов при 1,7-2,9 мин (табл.). Структурную идентификацию ГК (М.в. 170) проводили по данным МС-, УФ-спектроскопии: пики с $\mathrm{m} / \mathrm{z} 169[\mathrm{M}-\mathrm{H}]^{+}, \mathrm{m} / \mathrm{z} 125$ [M-H- $\left.\mathrm{CO}_{2}\right]$ являются индикаторами триоксифенольной части молекулы ГК и соответствуют ее молекулярной формуле $-\mathrm{C}_{7} \mathrm{H}_{6} \mathrm{O}_{5}$. В УФ-спектрах ГК, обнаруженной в этилацетатных фракциях исследуемых средств, наблюдается характерная для этого вещества полоса поглощения при 212-220, $269-270$ нм.

В сборе №1 источником ГК являются листья V. vitis-idaea [9], M. piperita [10]. Высоким содержанием ГК отличаются сборы № 3, 4, 6, в состав которого входят черные листья B. crassifolia содержащие ГК в свободном виде, а также в больших количествах галлотаннины, в которых ГК является структурным звеном [11]. Галлотаннины содержатся и в других компонентах сборов: V. vitis-idaea, C. sativum, Z. officinale, T. vulgaris [12]. В составе сбора №5 источниками свободной ГК являются C. sativum и H. rhamnoides [13, 14]. В плодах H. rhamnoides ГК содержится в свободном виде и в составе сложных эфиров [14]. Листья $U$. dioica являются источником свободной ГК [15] в сборе №2 и эритрофите.

\section{Bblводы}

Таким образом, наибольшее количество галловой кислоты содержится в сборах, в состав которых входят листья Bergenia crassifolia (L.) Fritsch., Urtica dioica L., Mentha piperita L., плоды Hippophae rhamnoides L.

\section{Список литературы}

1. Kumagai J., Kawaura T., Miyazaki T., Prost M., Prost E., Watanabe M., Quetin-leclercq J. Test for antioxidant ability by scavenging long-lived mutagenic radicals in mammaliam cells and by blood test with intentional radicals: an application of gallic acid // Radiation Physics and Chemistry. 2003. Vol. 66. Pp. 17-25.

2. Niho N., Shibutani M., Tamura T., Toyoda K., Uneyama C., Tanahashi N., Hirose M. Subchronic toxicity study of gallic acid by oral administration in F344 rats // Food and Chemical Toxicology. 2001. Vol. 39, N11. Pp. 1063-1070.

3. Giftson J.S., Jayanthi S., Nalini N. Chemopreventive efficacy of gallic acid, an antioxidant and anticarcinogenic polyphenol, against 1,2-dimethyl hydrazine induced rat colon carcinogenesis // Invest New Drugs. Preclinical studies. 2009. $10 \mathrm{pp}$.

4. Yen G.-C., Duh P.-D., Tsai H.-L. Antioxidant and pro-oxidant properties of ascorbic acid and gallic acid // Food Chemistry. 2002. Vol. 79. Pp. 307-313.

5. Yoshino M., Haneda M., Naruse M., Htay H.H., Iwata S., Tsubouchi R., Murakami K. Prooxidant action of gallic acid compounds: copper-dependent strand breaks and the formation of 8-hydroxy-2'-deoxyguanosine in DNA // Toxicology in vitro. 2002. Vol. 16. Pp. 705-709.

6. Zong Li, Makoto I., Mitsuhiko N., KeisukeK., Nahoko S., Kasuto I., Tahahiro T., Yukio O. Metabolic fate of gallic acid orally administered to rats // Biol. and Pharm. Bull. 1999. Vol. 22. N3. Pp. 326-329.

7. Гунькин И.Н. Оценка качества коньяков электрофоретическим и спектроскопическим методами: автореф. дис. ... канд. хим. наук. Краснодар, 2010. 25 с.

8. Руководство по методам контроля качества и безопасности биологически активных добавок к пище. Руководство P.4.1.1672-03. М., 2003.

9. Yan W., Zhou L., Deng G., Wang P., Creech D., Li S. Anthocyanins, phenolics, and antioxidant capacity of Vaccinium L. in Texas, USA // Pharmaceutical crops. 2011. Vol. 2. Pp. 11-23.

10. Зинченко Л.А. Изучение промышленных отходов фармацевтического производства как дополнительных источников биологически активных соединений (на примере шрота плодов боярышника и шрота листьев мяты) : автореф. дис. ... канд. фарм. наук. Пятигорск, 2007. 19 с.

11. Лубсандоржиева П.Б. Фитохимическая характеристика листьев бадана толстолистного и получение адаптогенного средства : автореф. дис. ... канд. фарм. наук. Улан-Удэ, 1997. 18 с.

12. Suhaj M. Spice antioxidant isolation and their antiradical activity: a review. // Journal of Food Composition and Analysis. 2006. Vol. 19. Pp. 531-537. 
13. Нерсесян 3. М. Химическое исследование травы кориандра посевного (Coriandrum sativum) с целью получения фармакологически активных веществ : автореф. дис. ... канд. фарм. наук. Пятигорск, 2007. 23 с.

14. Zadernowski R., Naczk M., Czaplicki S., Rubinskene M., Szatkiewicz M. Composition of phenolic acids in sea buckthorn (Hippophae rhamnoides L.) berries // JAOCS. 2005. Vol. 82. Pp. 175-179.

15. Головкин Б.Н., Руденская Р.Н., Трофимова И.А., Шретер А.И. Биологически активные вещества растительного происхождения. М., 2001. Т. 1. 350 с.; Т. 2.764 с.

Поступило в редакичию 12 сентября 2012 г.

Lubsandorzhieva P.B. ${ }^{{ }^{*},}$ Boldanova N.B. ${ }^{2}$, Popov D.V. ${ }^{2}$ DETERMINATION OF GALLIC ACID IN MULTICOMPONENT PREPARATIONS BY HPLC METHOD

${ }^{1}$ Institute of General and Experimental Biology, Siberian Branch, Russian Academy of Sciences, ul. Sakh"ianovoi, 6,

Ulan-Ude, 670047 (Russia)

${ }^{2}$ The Baikal Institute of Nature Management Siberian Branch, Russian Academy of Sciences, ul. Sakh"ianovoi, 6, Ulan-

Ude, 670047 (Russia),e-mail: bpunsic@mail.ru

The content of gallic acid in multicomponent remedies is defined by HPLC method. The greatest number of gallic acid contains in remedy including leaves of Bergenia crassifolia (L.) Fritsch., Urtica dioica L., Mentha piperita L., fruits of Hippophae rhamnoides $\mathrm{L}$. rhamnoides $\mathrm{L}$.

Keywords: gallic acid, HPLC, Bergenia crassifolia (L.) Fritsch., Urtica dioica L., Mentha piperita L., Hippophae

\section{References}

1. Kumagai J., Kawaura T., Miyazaki T., Prost M., Prost E., Watanabe M., Quetin-leclercq J. Radiation Physics and Chemistry, 2003, vol. 66, pp. 17-25.

2. Niho N., Shibutani M., Tamura T., Toyoda K., Uneyama C., Tanahashi N., Hirose M. Food and Chemical Toxicology, 2001, vol. 39, no. 11, pp. 1063-1070.

3. Giftson J.S., Jayanthi S., Nalini N. Invest New Drugs. Preclinical studies, 2009. 10 pp.

4. Yen G.-C., Duh P.-D., Tsai H.-L. Food Chemistry, 2002, vol. 79, pp. 307-313.

5. Yoshino M., Haneda M., Naruse M., Htay H.H., Iwata S., Tsubouchi R., Murakami K. Toxicology in vitro, 2002, vol. 16, pp. 705-709.

6. Zong Li, Makoto I., Mitsuhiko N., KeisukeK., Nahoko S., Kasuto I., Tahahiro T., Yukio O. Biol. and Pharm. Bull., 1999, vol. 22, no. 3, pp. 326-329.

7. Gun'kin I.N. Otsenka kachestva kon'iakov elektroforeticheskim i spektroskopicheskim metodami: avtoref. dis. ... kand. khim. nauk. [Assessment of quality cognacs electrophoretic and spectroscopic methods: the dissertation author's Ph.D.]. Krasnodar, 2010. 25 p. (in Russ.).

8. Rukovodstvo po metodam kontrolia kachestva i bezopasnosti biologicheski aktivnykh dobavok $k$ pishche. Rukovodstvo R.4.1.1672-03. [Guidance on how to control the quality and safety of dietary supplements to food. Guide R.4.1.1672-03.]. Moscow, 2003. (in Russ.).

9. Yan W., Zhou L., Deng G., Wang P., Creech D., Li S. Pharmaceutical crops., 2011, vol. 2, pp. 11-23.

10. Zinchenko L.A. Izuchenie promyshlennykh otkhodov farmatsevticheskogo proizvodstva kak dopolnitel'nykh istochnikov biologicheski aktivnykh soedinenii (na primere shrota plodov boiaryshnika i shrota list'ev miaty): avtoref. dis. ... kand. farm. nauk. [The study of industrial waste pharmaceutical production as additional sources of biologically active compounds (for example, hawthorn fruit meal and meal mint leaves): the dissertation author's Ph.D.]. Pyatigorsk, 2007, 19 p. (in Russ.).

11. Lubsandorzhieva P.B. Fitokhimicheskaia kharakteristika list'ev badana tolstolistnogo i poluchenie adaptogennogo sredstva: avtoref. dis. ... kand. farm. nauk. [Phytochemical characterization crassifolia leaves and getting adaptogenic means: the dissertation author's Ph.D.]. Ulan-Ude, 1997, 18 p. (in Russ.).

12. Suhaj M. Journal of Food Composition and Analysis, 2006, vol. 19, pp. 531-537.

13. Nersesian Z.M. Khimicheskoe issledovanie travy koriandra posevnogo (Coriandrum sativum) s tsel'iu polucheniia farmakologicheski aktivnykh veshchestv: avtoref. dis. ... kand. farm. nauk. [Chemical study of grass seed coriander (Coriandrum sativum) to produce pharmacologically active substances: the dissertation author's Ph.D.]. Pyatigorsk, 2007, 23 p. (in Russ.).

14. Zadernowski R., Naczk M., Czaplicki S., Rubinskene M., Szatkiewicz M. JAOCS, 2005, vo 1. 82, pp. 175-179.

15. Golovkin B.N.,. Rudenskaia R.N, Trofimova I.A., Shreter A.I. Biologicheski aktivnye veshchestva rastitel'nogo proiskhozhdeniia. [Biologically active substances of plant origin.]. Moscow, 2001, vol. 1, 350 p.; vol. 2, 764 p. (in Russ.).

\footnotetext{
* Corresponding author.
} 